\title{
Maillard and grilled steak challenge
}

\author{
Hervé This ${ }^{1}$
}

(C) Springer-Verlag Berlin Heidelberg 2015

We would like to invite you to participate in the Analytical Challenge, a series of puzzles to entertain and challenge our readers. This special feature of "Analytical and Bioanalytical Chemistry" has established itself as a truly unique quiz series, with a new scientific puzzle published every other month. Readers can access the complete collection of published problems with their solutions on the ABC homepage at http://www. springer.com/abc. Test your knowledge and tease your wits in diverse areas of analytical and bioanalytical chemistry by viewing this collection.

In the present challenge, the Maillard reaction is the topic. And please note that there is a prize to be won (a Springer book of your choice up to a value of $€ 100)$. Please read on...

\section{Meet the Maillard and grilled steak challenge}

After having been ignored for decades, Maillard processes are now in vogue in food science and technology. Here we suggest the reader recognizes that the Maillard reaction is only partially responsible for the wealth of compounds which are formed during cooking. The essential question is "how much"? In this vein, a scientific meeting on this topic is organized in France in September 2015, with the French Academies of Agriculture and Pharmacy.

Hervé This

herve.this@paris.inra.fr

1 INRA/AgroParisTech UMR 1145 Ingénierie Procédés Aliments, Group of Molecular Gastronomy, 16 rue Claude Bernard, F-75005 Paris, France
It all began in 1908, when Ling and Malting showed that the brown color in beer is due to the reaction of sugars and amino groups [1]. But the general name of such processes honors the French physician and chemist Louis Camille Maillard (1878-1936). While at the University of Nancy in Lorraine, then in Paris, he discovered that a brown color appeared when reducing sugars where heated with amino acids or proteins. This was published under the title "Action de la glycérine et des sucres sur les acides $\alpha$-aminés: cyclo-glycylglycines et polypeptides; mélanoïdines et matières humiques" on 8 January 1912 [2].

World War I as well as some love affairs (Maillard divorced, and left for Algeria) is likely responsible for the fact that Maillard stopped his research [3], with the consequence that the Maillard reactions were only recognized in food science after World War II [3]. But now, there is an International Maillard Reaction Society (IMARS), having its own publication, and most textbooks in food science discuss the importance of these chemical processes, perhaps adding too much emphasis [4]. Indeed, some food chemists even consider caramelization as a Maillard process [5], and Maillard processes are often considered as responsible for such products as 5-hydroxymethylfurfural, even if they can be made by many other processes, such as dehydration, pyrolysis, or thermolysis, none of which involve reaction between reducing sugars and amino acids [5].

In order to avoid having too broad a category, the term "Maillard reaction" should be used only when referring to molecular interactions initiated between an amino group and an $\alpha$-hydroxycarbonyl moiety of a reducing sugar [6]. The first intermediate of such interaction is a Schiff base, from which known Amadori and Heyns' rearrangement products appear (Fig. 1).

A complexity arises because this first step is followed by a cascade of other processes, including products formed 
Fig. 1 Maillard processes occur when an amino acid reacts with a reducing sugar (top glucose, i.e., an aldose; bottom fructose, i.e., a ketose), forming a Schiff base. The formed aldimine or ketimine is later transformed into an Amadori (ketosamine) or Heyns (aldosamine) compound, respectively
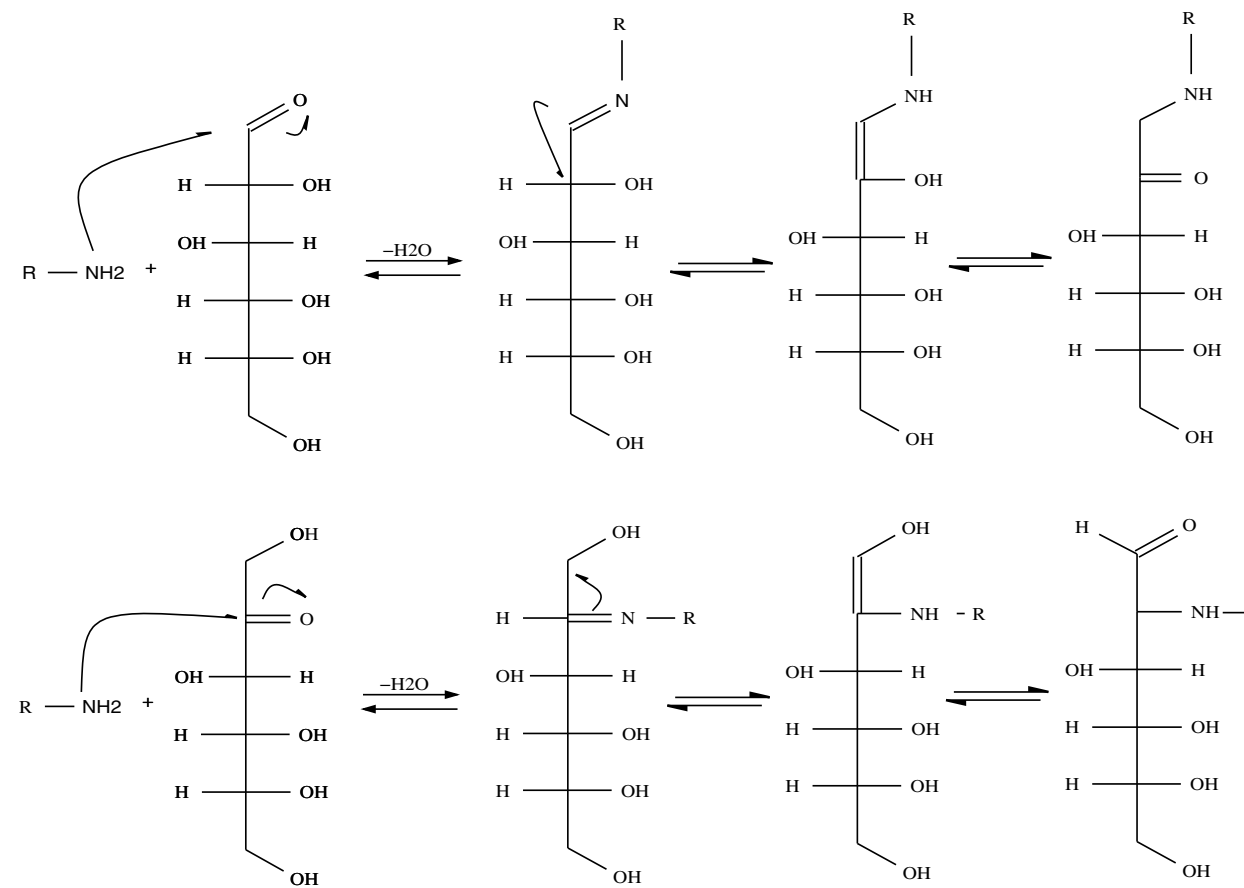
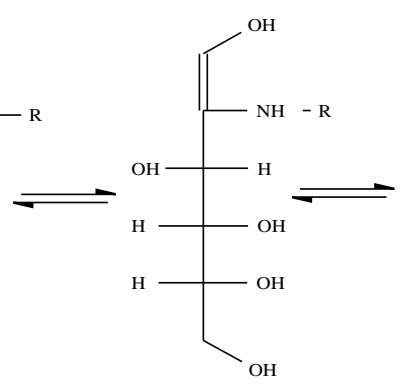

through the independent degradation of sugars or of amino acids, but it would be important for food science that we could assess quantitatively the real importance of Maillard reactions for the final result obtained through thermal processing of real food, and not only model systems.

With this challenge we propose something different from past challenges of this journal: the query put forward has no solution as of today, and we invite the reader to make a new scientific contribution in the proposed direction. This direction is open, and one should feel free to propose a solution which would not entirely answer the following very broad question: how much is the Maillard reaction responsible for the difference between a grilled steak and a raw steak?

One could focus on color, odor, or nutrients. Considering color, for example, one can ask: what proportion of the brown color is due to Maillard processes? The question is not simple, as many organic compounds heated in water turn brown; for example, many colored products appear to be (retro)aldolization/dehydration products of sugars which may or may not be attached to proteins or other sources of amino nitrogen [7, 8]. One could also focus on one particular compound, such as 5-HMF [9], which could arise from dehydration of fructose, from glucose, or cellulose [10]. 5-HMF could also be further decomposed into oximes [11], phenylhydrazone [12], p-nitrophenylhydrazone [13], semioxamazone [14], semicarbazone [15], or azine [16]. Concerning this particular compound, the question is: what proportion of 5-HMF present in meat after the grilling process is due to Maillard reactions, and how much is due to other processes?

\section{The challenge}

How much is the Maillard reaction responsible for the change in sensory properties or composition of muscular tissue from Bos taurus thermally processed by contact with a hot surface (i.e., grilling)?

\section{References}

1. Ling AR, Malting J (1908) J Inst Brew 14:494-521

2. Maillard L-C (1912) Action Des Acides Amines Sur Les Sucres. Formation Des Melanoidins Par Voie Methodique. Compt Rendus 154:66-68

3. Rivail JL (2015) Louis Camille Maillard, "bienfaiteur de l'humanité". Communication de l'Académie Stanislas, Nancy, 15 April 2005

4. Hodge JE (1953) Chemistry of browning reactions in model systems. J Agric Food Chem 1:928-943 
5. Smets K, Schreurs S, Carleer R, Yperman J (2014) Valorization of raspberry seed cake by flash and slow pyrolysis: product yield and characterization of the liquid and solid fraction. doi:10.1016/j.jaap. 2014.03.014

6. Yaylayan V (1997) Classification of the Maillard reaction: a conceptual approach. Trends Food Sci Technol 8:13-18

7. Rizzi GP (1997) Chemical structure of coloured maillard reactions products. Food Rev Int 13:1-28

8. Hoffman T (1999) Quantitative studies on the role of browning percursores in the Maillard reaction of pentoses and hexoses with L-alanine. Eur J Food Technol 209:113-121

9. Despax-Machefel S (2013) Développement de méthodologies de synthèse d'hydroxymethylfurfural à partir de biomasse lignocellulosique. PhD Reims-Champagne Ardennes University, 15 December 2013

10. Lewkowski H (2001) Synthesis, chemistry and applications of 5hydroxymethyl-furfural and its derivatives. Arkivoc I:17-54

11. Bonner WA, Roth MJ (1959) Am Chem Soc 81:5454

12. Cottier L, Descotes G, Neyret C, Nigay H (1989) Ind Aliment Agric 106:567-570

13. Bonner TG, Bourne EJ, Ruszkiewicz M (1960) J Chem Soc 787-791
14. Morikawa S (1978) Noguchi Kenkyusho Jiho 21:25-33

15. Mednick ML (1961) Chem Eng News 11:75

16. Mednick MLJ (1962) Org Chem 27:398-403

We invite our readers to participate in the Analytical Challenge by solving the puzzle above. Please send the correct solution to abc-challenge@springer.com by August 1, 2015. Make sure you enter "Maillard and grilled steak challenge" in the subject line of your e-mail. The winner will be notified by e-mail and his/her name will be published on the "Analytical and Bioanalytical Chemistry" homepage at http://www. springer.com/abc and in the journal (volume 407/issue 27) where readers will find the solution and a short explanation.

The next Analytical Challenge will be published in 407/22, September 2015. If you have enjoyed solving this Analytical Challenge you are invited to try the previous puzzles on the ABC homepage. 